\title{
The Influence of Histologic Inflammation on the Improvement of Liver Stiffness Values Over 1 and 3 Years
}

\author{
Jeong-Ju Yoo ${ }^{1}{ }^{\mathbb{D}}$, Yeon Seok Seo ${ }^{2}$, Young Seok Kim ${ }^{1}$, Soung Won Jeong ${ }^{3}$, Jae Young Jang ${ }^{3}$, \\ Sang Jun Suh ${ }^{4}$, Hyung Joon Yim ${ }^{4}$, Ki Tae Suk ${ }^{5}{ }^{(D)}$, Dong Joon Kim ${ }^{5}$ (D), Kwang-Hyub Han ${ }^{6}{ }^{(D)}$, \\ Seung Up Kim ${ }^{6}{ }^{\mathbb{D}}$, Bora Lee ${ }^{7} \mathbb{D}$, Sang Gyune Kim ${ }^{1, *}$ \\ and The Korean Transient Elastography Study Group ${ }^{\dagger}$
}

1 Division of Gastroenterology and Hepatology, Department of Internal Medicine, Soonchunhyang University Bucheon Hospital, Bucheon 14854, Korea; puby17@naver.com (J.-J.Y.); liverkys@schmc.ac.kr (Y.S.K.)

2 Division of Gastroenterology and Hepatology, Department of Internal Medicine, Korea University Anam Hospital, Korea University College of Medicine, Seoul 02841, Korea; drseo@korea.ac.kr

3 Division of Gastroenterology and Hepatology, Department of Internal Medicine, Soonchunhyang University Seoul Hospital, Seoul 04401, Korea; jeongsw@schmc.ac.kr (S.W.J.); jyjang@schmc.ac.kr (J.Y.J.)

4 Division of Gastroenterology and Hepatology, Department of Internal Medicine, Korea University Ansan Hospital, Korea University College of Medicine, Ansan 15459, Korea; mothpickle@naver.com (S.J.S.); gudwns21@korea.ac.kr (H.J.Y.)

5 Department of Internal Medicine, Chuncheon Sacred Heart Hospital, Hallym University College of Medicine, Chuncheon 24253, Korea; ktsuk@hallym.ac.kr (K.T.S.); djkim@hallym.ac.kr (D.J.K.)

6 Division of Gastroenterology, Department of Internal Medicine, Severance Hospital, Yonsei University College of Medicine, Seoul 03722, Korea; gihankhys@yuhs.ac (K.-H.H.); ksukorea@yuhs.ac (S.U.K.)

7 Department of Biostatistics, Graduate School of Chung-Ang University, Seoul 06974, Korea; mintbora0125@gmail.com

* Correspondence: mcnulty@schmc.ac.kr; Tel.: +82-32-621-5215; Fax: +82-32-621-6079

+ Membership of the The Korean Transient Elastography Study Group is provided in the Acknowledgements.

Received: 6 November 2019; Accepted: 20 November 2019; Published: 24 November 2019

Abstract: Background: Transient elastography is now an indispensable tool for estimating liver fibrosis. Although many clinical factors other than fibrosis itself are known to affect liver stiffness (LS) values, it is still not yet clear what factors are related to improving LS values. The aim of this study was to find out how baseline histologic inflammation influences LS values and how much this inflammation affects improvement in LS values over time, regardless of actual fibrosis content. Methods: This retrospective study included 678 consecutive patients who underwent liver biopsy and sequential LS assessment from 2006 to 2015 at six tertiary hospitals in Korea. Linear regression analysis was used to evaluate how improvement of LS value can be associated with other factors besides fibrosis content. Results: Basal LS values increased with increasing inflammation in the same fibrosis stage. Degree of inflammation influenced the baseline LS value in a proportional manner (beta coefficient (BE), 6.476; 95\% confidence interval (CI), 2.24-10.72; $p=0.003$ ). Moreover, histologic inflammation affected the change in LS value significantly. Higher inflammation grade at baseline was a significant predictor for an improvement in LS value, regardless of the fibrosis stage (BE, -8.581 ; $95 \% \mathrm{CI},-15.715--1.447 ; p=0.019)$. In a subgroup analysis of patients who received repeated liver biopsies, the results showed a similar tendency. Conclusions: The LS value is affected by the degree of inflammation even at a low ALT level. Furthermore, baseline histologic inflammation has a significant impact on the improvement of LS values over time. Therefore, baseline inflammation should be taken into consideration when interpreting an improvement in LS value.

Keywords: transient elastography; inflammation; liver biopsy 


\section{Introduction}

Transient elastography (TE; FibroScan ${ }^{\circledR}$, Echosens, France) is the most commonly used noninvasive method for the assessment of liver fibrosis. However, the value of liver stiffness (LS) measured by TE is influenced by many factors other than fibrosis content. Typical confounding factors are hepatitis, mechanical cholestasis, liver congestion, cellular infiltration, and fat deposition. Among these, inflammation may increase the LS value through hepatocellular swelling and hepatic infiltration of the inflammatory cell [1,2]. Based on LS values continuously measured in the same patient, it was found that the lower the alanine aminotransferase (ALT) value, the lower the LS value. Likewise, since LS measurements (LSMs) by TE under hepatic inflammation are prone to overestimation, accurate assessment of the amount of intrahepatic fibrosis is hindered under these circumstances. In a previous study, LS value was estimated to increase by about 4 kilopascals $(\mathrm{kPa})$ when ALT levels increased by about $100 \mathrm{U} / \mathrm{L}$. That study suggested that valid assessment of fibrosis stage cannot be made by TE when ALT is greater than $100 \mathrm{U} / \mathrm{L}$ [2]. In another study, necroinflammation was found to be the main cause of discrepancies between liver biopsy results and LS values [3]. However, ALT is not the only factor that points to biochemical inflammation. In addition, ALT level does not always accurately reflect the severity of hepatitis. Previous studies have also shown that antiviral use, duration of therapy, higher initial LSM value, and hepatitis B virus (HBV) DNA levels are associated with improvements in measured LS values for patients with chronic hepatitis B (CHB) [4-6]. It is well known that inflammation affects LS values, but little research has been undertaken on how much histological inflammation contributes to the improvement of LS values. Several studies have shown that increased liver enzyme levels or elevated intrahepatic inflammation contribute to an increase of LSMs $[7,8]$. However, there is very little research showing that the degree of inflammation found in a liver biopsy actually affects the LS value and how changes in that LS value after long-term follow-up are closely related with the initial degree of inflammation. Our hypothesis was that LS is influenced not only by liver fibrosis, but also by inflammation and that patients with higher grade inflammation during baseline measurements would show a greater improvement in LS values regardless of actual fibrosis content. The aim of this study was to determine whether baseline hepatic inflammation affects LS measurements, independent of fibrosis stage, and identify factors associated with improvement in LS value over time.

\section{Methods}

\subsection{Patients and Study Protocol}

Between January 2006 and August 2015, we collected data from patients with chronic liver disease during routine clinical care at six tertiary hospitals. These data were taken from the electronic database of the Korean Transient Elastography Study Group. Patients who fulfilled the following inclusion criteria were eligible for this study: (a) patients who were clinically, pathologically, or radiologically diagnosed with chronic liver disease or liver cirrhosis; (b) patients who underwent an initial baseline liver biopsy; and (c) patients with repeated measurement of LS, including a baseline LS value taken at the time of their initial liver biopsy. Patients who met the following conditions were excluded from the study: (a) those who failed LSM; (b) those with aspartate aminotransferase (AST) or ALT levels of more than 5 times the upper limit of normal; (c) those who had inadequate liver biopsy samples; (d) those whose baseline liver biopsy data and baseline LSMs were more than 3 months apart; (e) those found to have hepatocellular carcinoma at enrollment or during follow-up; (f) patients whose repeated TE measurement was performed less than one year from their baseline LSM; or (g) patients who received antiviral therapy for hepatitis B or hepatitis $C$ for less than one year. Finally, we retrospectively included 678 patients who met the criteria. The clinical, histological, and laboratory records of these patients were retrospectively reviewed. 
This study's protocol was approved by the institutional review board of SoonChunHyang University Bucheon Hospital (IRB number SCHBC 2018-01-001-001). The study protocol conformed to ethical guidelines set by the World Medical Association Declaration of Helsinki.

\subsection{Liver Biopsy and Histology}

Liver biopsy was performed when each patient's doctor deemed it necessary to determine the cause and severity of their liver disease. Specimens were fixed in formalin and embedded in paraffin. Sections were stained with hematoxylin-eosin and Masson's trichrome. Each biopsy specimen was analyzed by an experienced pathologist at each hospital. All pathologists were unaware of the TE results. Fibrosis was assessed to be at a stage from 0 to 4 on a scale using the METAVIR criteria where: F0, no fibrosis; F1, portal fibrosis without septa; F2, periportal fibrosis; F3, septal fibrosis; F4, liver cirrhosis. Histologic inflammation was graded using a modified histological index (HAI) $[9,10]$; none or minimal inflammation (inflammation score 0-4), mild (inflammation score 5-8), moderate (inflammation score 9-12), and severe (inflammation score 13-18). Specimens of at least $20 \mathrm{~mm}$ in length were considered eligible for interpretation in this study [11].

\subsection{Transient Elastography}

LS was measured by Fibroscan ${ }^{\circledR}$ using M probe as reported previously [12]. Forty-two (6.2\%) patients who did not qualify for $\mathrm{M}$ probe were measured by XL probe. The success rate was calculated as the number of valid measurements divided by the total number of measurements. Ten measurements were performed with a success rate of at least $60 \%$. Results are expressed as $\mathrm{kPa}$. The median value was taken as the representative value. Interquartile range (IQR) was defined as the index of intrinsic variability in the LS values and corresponds to the interval between the 25th and 75th percentiles, which contains $50 \%$ of the valid LSMs taken. Only procedures with at least ten valid measurements and a IQR/median value $<0.3$ were considered. LSMs were performed by expert physicians who had experience conducting these tests on more than 1000 cases. Improvement of LS value was defined as decrease of LS value compared to the previous ones.

\subsection{Statistical Analysis}

Frequencies and percentages were used for descriptive statistics. Statistical differences between groups were investigated using the $\chi^{2}$ test and Student's $t$-test. Spearman's analysis was used to investigate correlations between variables. To identify predictive factors associated with 1-year improvement in TE, logistic regression analysis was used. Multivariate models were created using variables that were significant $(p<0.10)$ in univariate analysis and clinically relevant. All statistical analyses were performed using R (version 3.3.3, The R Foundation for Statistical Computing, Vienna, Austria) and SPSS software (version 21.0; SPSS Inc., Chicago, IL, USA). Statistical significance was defined at $p<0.05$.

\section{Results}

\subsection{Baseline Characteristics}

Baseline demographics and clinical characteristics of patients are summarized in Table 1. A total of 678 patients were analyzed, $329(48.5 \%)$ were male and $349(51.5 \%)$ were female. Mean age of these patients was $47.12 \pm 12.25$ years, with mean body mass index (BMI) of $23.97 \pm 3.44 \mathrm{~kg} / \mathrm{m}^{2}$. The most common cause of liver disease was HBV (61.8\%), followed by hepatitis C virus (HCV) $(27.0 \%)$, and then others (11.2\%). Mean AST and ALT levels were $44 \mathrm{U} / \mathrm{L}$ and $46 \mathrm{U} / \mathrm{L}$, respectively.

Distributions for fibrosis stage, steatosis, and inflammation grade in the study population are also presented in Table 1. The median LS value was $10.50 \mathrm{kPa}$. Distributions of LS value according to fibrosis stage, inflammation grade, and steatosis grade are shown in Figure 1. Baseline LS values were significantly correlated with fibrosis stage ( $p<0.001$ for trend) and inflammation grade $(p=0.001$ 
for trend), but not with steatosis grade ( $p=0.101$ for trend) (Figure 1). Next, we investigated the distribution of LS value according to inflammation grade for patients in the same fibrosis stage (Supplementary Figure S1). LS values were higher with higher inflammation grades within a same fibrosis stage (Supplementary Figure S1).
(A) Fibrosis stage
(B) Inflammation grade
(C) Steatosis grade
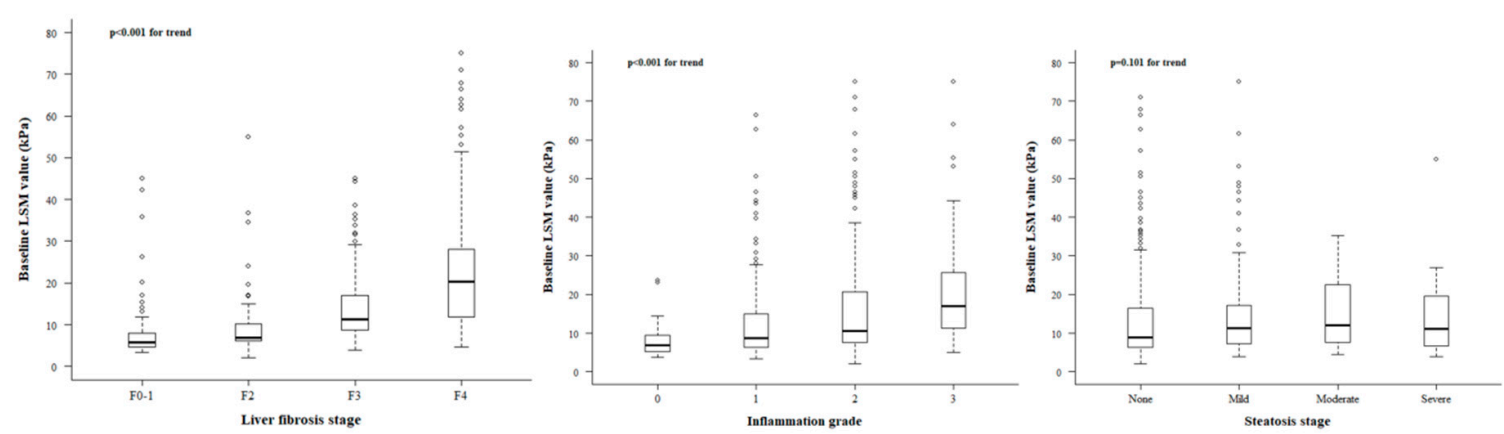

Figure 1. Distribution of liver stiffness (LS) values according to histologic findings. Distributions of LS values according to (A) fibrosis stage, (B) inflammation grade, and (C) steatosis stage are described in this figure. The length of the box represents the interquartile range, within which $50 \%$ of the value is located. The line through the middle of each box represents the median. Error bars show the minimum and maximum values (range).

Table 1. Baseline characteristics of patients.

\begin{tabular}{|c|c|c|c|}
\hline Variable & Baseline $(n=678)$ & 1-year $(n=358)$ & 3-year $(n=244)$ \\
\hline Age, year, mean (SD) & $47.12(12.25)$ & $48.54(11.84)$ & $49.57(10.42)$ \\
\hline \multicolumn{4}{|l|}{ Sex, n (\%) } \\
\hline Male & $329(48.5)$ & $181(50.6)$ & $120(49.2)$ \\
\hline Female & 349 (51.5) & $177(49.4)$ & $124(50.8)$ \\
\hline \multicolumn{4}{|l|}{ Etiology, n (\%) } \\
\hline HBV & $419(61.8)$ & $242(67.6)$ & $173(70.9)$ \\
\hline $\mathrm{HCV}$ & $183(27.0)$ & $70(19.6)$ & $49(20.1)$ \\
\hline Alcoholic & $12(1.8)$ & $7(2.0)$ & $5(2.0)$ \\
\hline Autoimmune & $32(4.7)$ & $21(5.9)$ & $8(3.3)$ \\
\hline NAFLD & $21(3.1)$ & $12(3.4)$ & $7(2.9)$ \\
\hline Others & $11(1.6)$ & $6(1.7)$ & $2(0.8)$ \\
\hline BMI, kg/m², mean (SD) & $23.97(3.44)$ & NA & NA \\
\hline \multicolumn{4}{|l|}{ Laboratory findings } \\
\hline AST, U/L, mean (IQR) & $44.0(30.0-77.0)$ & $37.0(22.0-38.0)$ & $28.0(17.0-30.0)$ \\
\hline ALT, U/L, mean (IQR) & $46.0(29.0-83.0)$ & $39.0(26.0-39.0)$ & $30.0(17.0-30.0)$ \\
\hline Total bilirubin, mg/dL, mean (SD) & $1.11(1.41)$ & $0.82(0.46)$ & $1.02(0.92)$ \\
\hline Albumin, mg/dL, mean (SD) & $4.15(0.53)$ & $4.35(0.34)$ & $4.34(0.34)$ \\
\hline Prothrombin time, INR, mean (SD) & $1.01(0.46)$ & $0.97(0.14)$ & $0.89(0.27)$ \\
\hline LSM value, kPa, mean (IQR) & $10.5(7.3-19.6)$ & $8.4(5.3-12.0)$ & $7.0(1.8-10.0)$ \\
\hline \multicolumn{4}{|l|}{ Liver biopsy, n (\%) } \\
\hline \multicolumn{4}{|l|}{ Fibrosis } \\
\hline F0 & $13(1.9)$ & & \\
\hline $\mathrm{F} 1$ & $96(14.2)$ & & \\
\hline $\mathrm{F} 2$ & $132(19.5)$ & & \\
\hline F3 & $186(27.4)$ & & \\
\hline $\mathrm{F} 4$ & $251(37.0)$ & & \\
\hline
\end{tabular}


Table 1. Cont.

\begin{tabular}{|c|c|c|c|}
\hline Variable & Baseline $(n=678)$ & 1 -year $(n=358)$ & 3 -year $(n=244)$ \\
\hline \multicolumn{4}{|l|}{ Steatosis } \\
\hline No steatosis & $370(64.2)$ & & \\
\hline Mild & $156(27.1)$ & & \\
\hline Moderate & $36(6.3)$ & & \\
\hline Severe & $14(2.4)$ & & \\
\hline \multicolumn{4}{|l|}{ Inflammation } \\
\hline No inflammation & $28(4.1)$ & & \\
\hline Mild & $278(41.0)$ & & \\
\hline Moderate & $279(41.2)$ & & \\
\hline Severe & $93(13.7)$ & & \\
\hline
\end{tabular}

$\mathrm{SD}$, standard deviation; HBV, hepatitis B virus; $\mathrm{HCV}$, hepatitis $\mathrm{C}$ virus; NAFLD, nonalcoholic fatty liver disease; BMI, body mass index; AST, aspartate aminotransferase; IQR, interquartile range; ALT, alanine aminotransferase; INR, international normalized ratio; LSM, liver stiffness measurement.

\subsection{Related Factors Determining Baseline LS Value}

Based on biopsy results and laboratory findings, factors affecting baseline LS values were examined using linear regression analyses (Table 2). It was found that LS values increased with increasing fibrosis (beta coefficient (BE), 8.306; 95\% confidence interval (CI), 2.730-13.882; $p=0.004$ ). Furthermore, the degree of inflammation increased the LS value in a dose-dependent manner, regardless of fibrosis stage, total bilirubin, albumin, prothrombin time, or serum sodium level (BE, 6.476; 95\% CI, 2.236-10.716; $p=0.003$ ). It was also found that LS values tend to be lower in viral etiology than that in nonviral etiology for patients in the same fibrosis stage (BE, -3.56 ; $95 \% \mathrm{CI},-5.994$ to $-1.125 ; p=0.004$ ).

Since previous studies have shown that high ALT affects LS values, we separately analyzed patients with ALT values below $40 \mathrm{U} / \mathrm{L}$. In 283 patients with normal ALT, fibrosis stage was well correlated with baseline LS value. In this group, histologic inflammation of greater than a moderate grade was also well correlated with LS value (Supplementary Table S1).

Table 2. Linear regression analysis for the factors associated with baseline liver stiffness values.

\begin{tabular}{|c|c|c|c|c|}
\hline \multirow{2}{*}{ Variable } & \multicolumn{2}{|l|}{ Univariable } & \multicolumn{2}{|l|}{ Multivariable } \\
\hline & $\beta(95 \% \mathrm{CI})$ & $p$ Value & $\beta(95 \% \mathrm{CI})$ & $p$ Value \\
\hline Age, year & $0.175(0.091$ to 0.258$)$ & $<0.001$ & & \\
\hline Sex, male & $0.158(-1.857$ to 2.174$)$ & 0.877 & & \\
\hline Viral etiology & $-5.530(-8.487$ to -2.573$)$ & $<0.001$ & $-3.560(-5.994$ to -1.125$)$ & 0.004 \\
\hline BMI, $\mathrm{kg} / \mathrm{m}^{2}$ & $0.115(-0.223$ to 0.452$)$ & 0.505 & & \\
\hline \multicolumn{5}{|l|}{ Laboratory findings } \\
\hline Platelet, $10^{9} / \mathrm{L}$ & $-0.073(-0.088$ to -0.058$)$ & $<0.001$ & $-0.024(-0.039$ to -0.010$)$ & 0001 \\
\hline AST, U/L & $0.011(0.005$ to 0.016$)$ & 0.001 & & \\
\hline ALT, U/L & 0.005 (0.000 to 0.009$)$ & 0.032 & & \\
\hline Total bilirubin, $\mathrm{mg} / \mathrm{mL}$ & $2.781(2.153$ to 3.409$)$ & $<0.001$ & $1.904(1.408$ to 2.400$)$ & $<0.001$ \\
\hline Albumin, mg/dL & $-12.387(-14.033$ to -10.741$)$ & $<0.001$ & $-5.120(-6.862$ to -3.378$)$ & $<0.001$ \\
\hline Prothrombin time, INR & $8.789(6.859$ to 10.719$)$ & $<0.001$ & 4.913 (3.411 to 6.415$)$ & $<0.001$ \\
\hline Creatinine, $\mathrm{mg} / \mathrm{dL}$ & $-0.706(-1.775$ to 0.363$)$ & 0.195 & & \\
\hline Sodium, mEq/L & $-1.428(-1.809$ to -1.047$)$ & $<0.001$ & $-0.494(-0.789$ to -0.198$)$ & 0.001 \\
\hline \multicolumn{5}{|l|}{ Liver biopsy } \\
\hline \multicolumn{5}{|l|}{ Fibrosis } \\
\hline F0 & 1 (reference) & & 1 (reference) & \\
\hline F1 & $-5.570(-12.045$ to 0.906$)$ & 0.092 & $-0.341(-5.928$ to 5.246$)$ & 0.905 \\
\hline $\mathrm{F} 2$ & $-3.765(-10.153$ to 2.622$)$ & 0.247 & $-1.240(-6.819$ to 4.340$)$ & 0.663 \\
\hline F3 & $1.072(-5.176$ to 7.319$)$ & 0.736 & $1.048(-4.544$ to 6.641$)$ & 0.713 \\
\hline $\mathrm{F} 4$ & 10.277 (4.048 to 16.506$)$ & 0.001 & 8.306 (2.730 to 13.882$)$ & 0.004 \\
\hline
\end{tabular}


Table 2. Cont.

\begin{tabular}{|c|c|c|c|c|}
\hline \multirow{2}{*}{ Variable } & \multicolumn{2}{|l|}{ Univariable } & \multicolumn{2}{|l|}{ Multivariable } \\
\hline & $\beta(95 \% \mathrm{CI})$ & $p$ Value & $\beta(95 \% \mathrm{CI})$ & $p$ Value \\
\hline \multicolumn{5}{|l|}{ Steatosis } \\
\hline No steatosis & 1 (reference) & & & \\
\hline Mild & $0.868(-1.562$ to 3.299$)$ & 0.483 & & \\
\hline Moderate & $1.247(-2.960$ to 5.455$)$ & 0.561 & & \\
\hline Severe & $1.339(-5.092$ to 7.770$)$ & 0.683 & & \\
\hline \multicolumn{5}{|l|}{ Inflammation } \\
\hline No inflammation & 1 (reference) & & 1 (reference) & \\
\hline Mild & $3.897(-1.265$ to 9.058$)$ & 0.139 & 2.347 ( -1.487 to 6.182$)$ & 0.230 \\
\hline Moderate & 7.414 (2.289 to 12.538$)$ & 0.005 & $3.374(-0.489$ to 7.237$)$ & 0.087 \\
\hline Severe & $11.492(5.977$ to 17.007$)$ & $<0.001$ & $6.476(2.236$ to 10.716$)$ & 0.003 \\
\hline
\end{tabular}

BMI, body mass index; AST, aspartate aminotransferase; ALT, alanine aminotransferase; INR, international normalized ratio; $\mathrm{CI}$, confidence interval.

\subsection{Factors Associated with Improvement of LS Value}

We then analyzed factors associated with LS improvement in patients who had received antiviral agents consistently along with follow-up LSMs. We were able to obtain a follow-up LS value after one year from 358 patients and three-year follow-up data from 244 patients. The rate of change in the LS value was linear over one and three years (Figure 2). We investigated the change in LS value according to inflammation grade after one and three years (Figure 3). The LS value tended to improve significantly in relation to the degree of basal inflammation found at one-year and three-year follow-ups (both $p<0.001$ ). Next, we performed linear regression analysis to find out which factors determine the change in LS value. The results of the linear regression analysis after one and three years are shown in Tables 3 and 4, respectively. In our multivariate analysis, the higher inflammation group showed greater improvement in LS value at both one-year (BE, $-8.581 ; 95 \% \mathrm{CI},-15.715-1.447 ; p=0.019$ ) and three-year follow-ups (BE, $-10.725 ; 95 \% \mathrm{CI},-19.299-2.151 ; p=0.014)$ after adjusting for other factors. In addition to inflammation, the factors related to changes in LS value were platelet levels (BE, 0.027; 95\% CI, 0.011-0.042; $p=0.001$ ), total bilirubin (BE, -1.716 ; 95\% CI, $-2.420--1.011 ; p<0.001$ ), and prothrombin time $(\mathrm{BE},-4.647 ; 95 \% \mathrm{CI},-6.126--3.167 ; p<0.001)$. Sensitivity analysis showed similar results with more significance (Supplementary Tables S2 and S3).

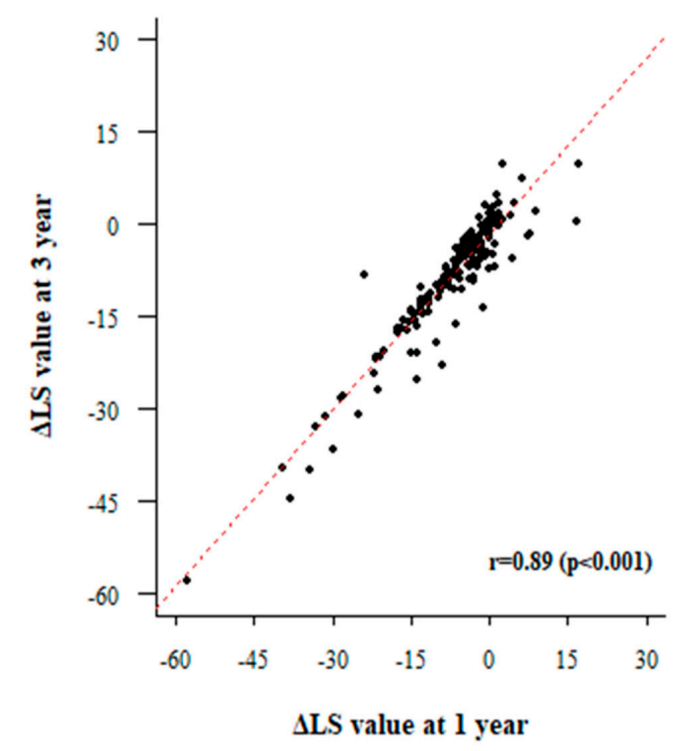

Figure 2. Correlation between 1-year liver stiffness value change and 3-year LS value change. 
(A) 1-year follow-up

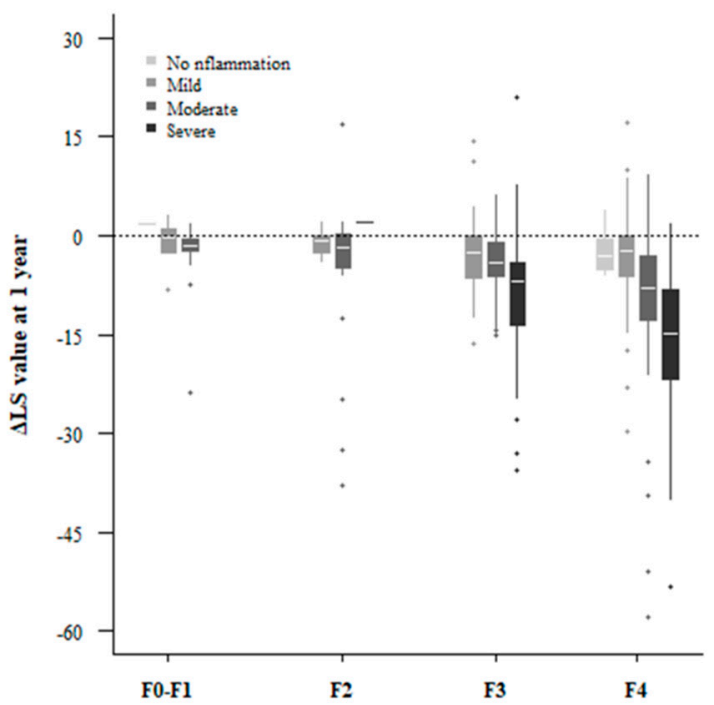

(B) 3-year follow-up

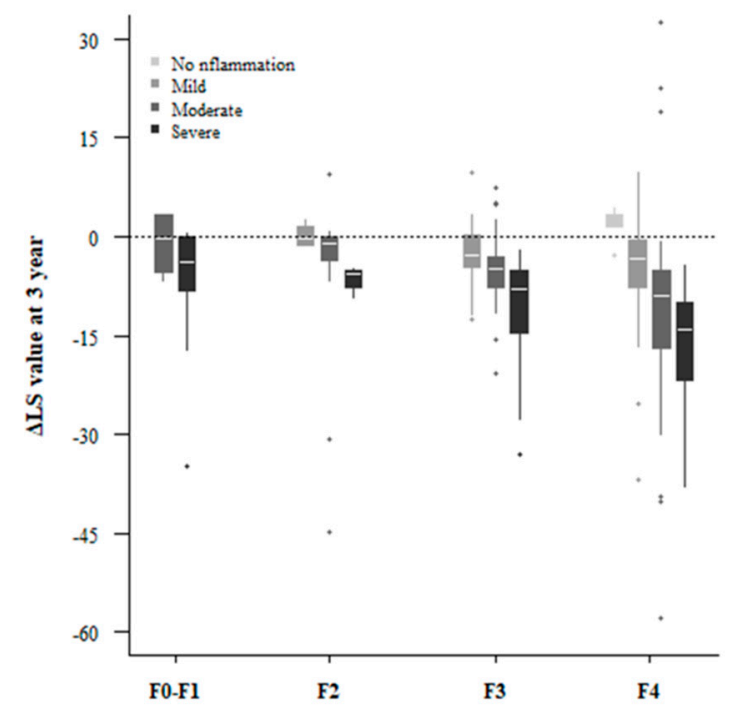

Figure 3. Change in liver stiffness value after (A) 1 year and (B) 3 years according to baseline fibrosis stage and inflammation grade.

Table 3. Linear regression analysis on 1-year liver stiffness value change amount.

\begin{tabular}{|c|c|c|c|c|}
\hline \multirow{2}{*}{ Variable } & \multicolumn{2}{|l|}{ Univariable } & \multicolumn{2}{|l|}{ Multivariable } \\
\hline & $\beta(95 \% \mathrm{CI})$ & $p$ Value & $\beta(95 \% \mathrm{CI})$ & $p$ Value \\
\hline Age, year & $-0.028(-0.115,0.060)$ & 0.535 & & \\
\hline Sex, male & $0.263(-1.785,2.311)$ & 0.801 & & \\
\hline Viral etiology & $3.527(0.489,6.566)$ & 0.023 & & \\
\hline BMI, $\mathrm{kg} / \mathrm{m}^{2}$ & $0.086(-0.274,0.446)$ & 0.638 & & \\
\hline \multicolumn{5}{|l|}{ Laboratory findings } \\
\hline Platelet, $10^{9} / \mathrm{L}$ & $0.025(0.008,0.043)$ & 0.005 & $0.027(0.011,0.042)$ & 0.001 \\
\hline AST, U/L & $-0.012(-0.018,-0.007)$ & $<0.001$ & & \\
\hline ALT, U/L & $-0.011(-0.017,-0.005)$ & $<0.001$ & & \\
\hline Total bilirubin, $\mathrm{mg} / \mathrm{mL}$ & $-1.830(-2.606,-1.055)$ & $<0.001$ & $-1.716(-2.420,-1.011)$ & $<0.001$ \\
\hline Albumin, mg/dL & $5.882(3.793,7.971)$ & $<0.001$ & & \\
\hline Prothrombin time, INR & $-5.399(-6.994,-3.803)$ & $<0.001$ & $-4.647(-6.126,-3.167)$ & $<0.001$ \\
\hline Creatinine, mg/dL & $3.825(-1.620,9.271)$ & 0.168 & & \\
\hline Sodium, mEq/L & $0.438(0.051,0.825)$ & 0.027 & & \\
\hline \multicolumn{5}{|l|}{ Liver biopsy } \\
\hline \multicolumn{5}{|l|}{ Fibrosis } \\
\hline F0 & 1 (reference) & & & \\
\hline $\mathrm{F} 1$ & $3.909(-4.872,12.691)$ & 0.382 & & \\
\hline F2 & $1.493(-6.893,9.880)$ & 0.726 & & \\
\hline F3 & $-0.692(-8.670,7.285)$ & 0.865 & & \\
\hline F4 & $-2.352(-10.337,5.633)$ & 0.563 & & \\
\hline \multicolumn{5}{|l|}{ Steatosis } \\
\hline No steatosis & 1 (reference) & & & \\
\hline Mild & $-0.855(-3.287,1.576)$ & 0.489 & & \\
\hline Moderate & $0.123(-3.929,4.174)$ & 0.952 & & \\
\hline Severe & $-3.166(-8.953,2.620)$ & 0.282 & & \\
\hline \multicolumn{5}{|l|}{ Inflammation } \\
\hline No inflammation & 1 (reference) & & 1 (reference) & \\
\hline Mild & $-1.312(-9.011,6.387)$ & 0.738 & $-1.256(-8.298,5.786)$ & 0.726 \\
\hline Moderate & $-3.925(-11.578,3.727)$ & 0.314 & $-3.196(-10.201,3.808)$ & 0.370 \\
\hline Severe & $-9.875(-17.673,-2.078)$ & 0.013 & $-8.581(-15.715,-1.447)$ & 0.019 \\
\hline
\end{tabular}

BMI, body mass index; AST, aspartate aminotransferase; ALT, alanine aminotransferase; OR, odds ratio; CI, confidence interval. 
Table 4. Linear regression analysis on 3-year liver stiffness value change amount.

\begin{tabular}{|c|c|c|c|c|}
\hline \multirow{2}{*}{ Variable } & \multicolumn{2}{|l|}{ Univariable } & \multicolumn{2}{|l|}{ Multivariable } \\
\hline & $\beta(95 \% \mathrm{CI})$ & $p$ Value & $\beta(95 \% \mathrm{CI})$ & $p$ Value \\
\hline Age, year & $-0.013(-0.137,0.11)$ & 0.832 & & \\
\hline Sex, male & $-2.451(-5.004,0.102)$ & 0.060 & & \\
\hline Viral etiology & $-2.200(-6.681,2.281)$ & 0.334 & & \\
\hline BMI, $\mathrm{kg} / \mathrm{m}^{2}$ & $0.042(-0.372,0.456)$ & 0.842 & & \\
\hline \multicolumn{5}{|l|}{ Laboratory findings } \\
\hline Platelet, $10^{9} / \mathrm{L}$ & $0.028(0.005,0.052)$ & 0.020 & & \\
\hline AST, U/L & $-0.013(-0.022,-0.005)$ & 0.003 & & \\
\hline ALT, U/L & $-0.005(-0.010,0.001)$ & 0.091 & & \\
\hline Total bilirubin, $\mathrm{mg} / \mathrm{mL}$ & $-1.638(-2.745,-0.531)$ & 0.004 & $-1.129(-2.153,-0.105)$ & 0.031 \\
\hline Albumin, mg/dL & $7.138(4.336,9.940)$ & $<0.001$ & $4.135(1.187,7.084)$ & 0.006 \\
\hline Prothrombin time, INR & $-7.089(-10.301,-3.876)$ & $<0.001$ & $-5.954(-8.978,-2.931)$ & $<0.001$ \\
\hline Creatinine, mg/dL & $1.223(-6.467,8.912)$ & 0.754 & & \\
\hline Sodium, mEq/L & $0.429(-0.108,0.967)$ & 0.117 & & \\
\hline \multicolumn{5}{|l|}{ Liver biopsy } \\
\hline \multicolumn{5}{|l|}{ Fibrosis } \\
\hline F0 & 1 (reference) & & & \\
\hline $\mathrm{F} 1$ & $2.625(-18.129,23.379)$ & 0.803 & & \\
\hline $\mathrm{F} 2$ & $4.321(-15.918,24.561)$ & 0.674 & & \\
\hline F3 & $1.288(-18.740,21.317)$ & 0.899 & & \\
\hline $\mathrm{F} 4$ & $-0.766(-20.821,19.289)$ & 0.94 & & \\
\hline \multicolumn{5}{|l|}{ Steatosis } \\
\hline No steatosis & 1 (reference) & & & \\
\hline Mild & $-1.600(-4.734,1.534)$ & 0.315 & & \\
\hline Moderate & $-1.515(-6.960,3.930)$ & 0.584 & & \\
\hline Severe & $-6.865(-13.645,-0.085)$ & 0.047 & & \\
\hline \multicolumn{5}{|l|}{ Inflammation } \\
\hline No inflammation & 1 (reference) & & 1 (reference) & \\
\hline Mild & $-5.772(-14.596,3.051)$ & 0.199 & $-4.631(-12.982,3.721)$ & 0.276 \\
\hline Moderate & $-8.888(-17.625,-0.151)$ & 0.046 & $-6.553(-14.959,1.852)$ & 0.126 \\
\hline Severe & $-13.894(-22.773,-5.015)$ & 0.002 & $-10.725(-19.299,-2.151)$ & 0.014 \\
\hline
\end{tabular}

BMI, body mass index; AST, aspartate aminotransferase; ALT, alanine aminotransferase; OR, odds ratio; CI, confidence interval.

\subsection{Paired Liver Biopsy with Paired LSM}

To accurately determine the effect of histological inflammation on LS values, we analyzed a subgroup of patients with paired liver biopsy and paired LS results (Figure 4). Follow-up biopsies were performed after a median period of two years (range one to eight years). Among the enrolled patients, there were 24 patients who had LSMs taken simultaneously with their repeated liver biopsies. A description of these 24 patients is presented in Supplementary Table S4. Among them, 12 patients showed improved LS values and 12 did not. Among the group with improved LS, 33.3\% showed an improvement in fibrosis stage and $41.6 \%$ showed an improvement in inflammation grade on their follow-up liver biopsy (Figure 4). However, in the group without an improvement in their LS, histologic fibrosis and inflammation was improved in only $16.7 \%$ and $25.0 \%$ of patients, respectively (Figure 4 ). Although the group with decreased LS showed a higher proportion of improvement of histological fibrosis $(33.3 \%$ vs. $16.7 \%)$ or inflammation ( $41.6 \%$ vs. $25.0 \%)$, these results were not statistically significant (fibrosis, $p=0.640$; inflammation, $p=0.667$ ). 


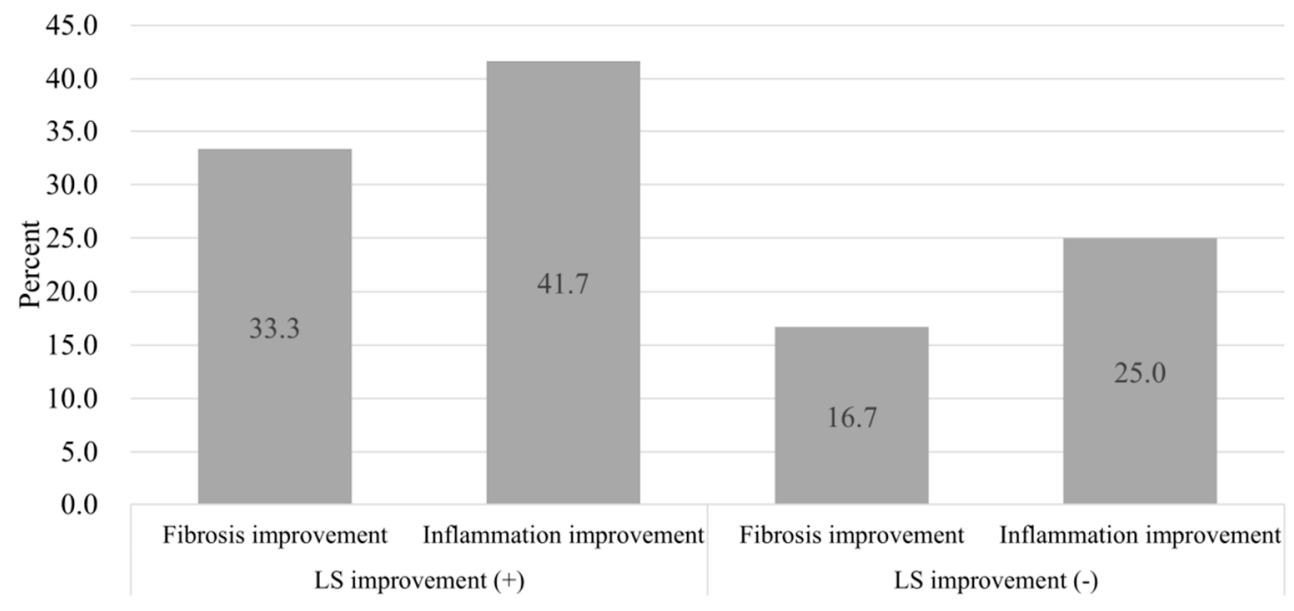

Figure 4. Change in liver stiffness value and histologic findings in patients who underwent repeated liver biopsies.

\section{Discussion}

TE was originally designed to accurately assess the amount of intrahepatic fibrosis without the need for invasive procedures. This procedure has now largely replaced biopsy for this purpose [13-15]. However, even if CHB patients with the same fibrosis stage and LS value are treated with the same antiviral drug, their improvements are different. Our research started with the question of why this difference would occur, despite the patients having the same fibrosis stage at baseline. Through this study, we found that LS values are affected even at low ALT level $(<40 \mathrm{IU} / \mathrm{L})$. Therefore, we need to pay attention to how we interpret LS values.

Many studies have reported that hepatic inflammation affects LS value, regardless of etiology $[1,11,16,17]$. However, previous reports were mainly focused on the association of LS values and ALT as an indicator of inflammation $[7,8,18]$. It is difficult to routinely perform liver biopsies except in patients with a specific indication. In this context, this study has important implications for evaluating whether a patient's LS value is associated with their histologic inflammation grade rather than their ALT level.

As mentioned in the results, the degree of histologic inflammation is correlated with the improvement in LS value, but not with ALT level. This may be due to the fact that ALT level is not directly correlated with histologic inflammation in liver disease. This phenomenon is well-known in the immune tolerance phase of HBV. It has also been reported in other etiologies [19]. In HCV and nonalcoholic fatty liver disease, ALT is not a reliable marker for reflecting the degree of inflammation [20-23]. In the same vein, we should note that histologic inflammation in autoimmune hepatitis lasts for a considerable period of time even after normalization of ALT by biochemical remission [24]. We also found that baseline histologic inflammation was an important confounding factor affecting both the baseline LSM and subsequent improvement in LSMs, regardless of etiology.

There are several hypotheses explaining the discrepancy between histologic inflammation and ALT level. The first hypothesis is that ALT elevation is related to the location of inflammation [25]. When lobular inflammation is predominant, ALT levels will rise due to hepatocellular injury. However, if inflammation occurs mainly in the periportal area, any ALT rise will not be so noticeable. The second hypothesis is that changes in ALT level seem to be faster than histologic changes, especially in cases of autoimmune hepatitis, where biochemical remission has been reported to progress several months earlier than histological remission [26]. Considering that inflammation is the main mechanism of autoimmune hepatitis, the same phenomenon may apply to other etiologies where inflammation plays an important role in the pathophysiology. Third, the location of fibrosis, especially perisinusoidal fibrosis, can matter. Fraquelli et al. proposed this very hypothesis, their reasoning was that 
perisinusoidal fibrosis is not reflected in the METAVIR system and thus makes the interpretation of this histological confounder even more difficult [27].

In previous reports, it was found that inflammation affects LS values at low fibrosis stages but not at high fibrosis stages $[3,28,29]$. However, our results show that inflammation increases the LS value regardless of fibrosis stage, even in the cirrhotic stage. Therefore, if it is indicated that a patient may have cirrhosis by an LS value over $12 \mathrm{kPa}$, it is necessary to repeat the LSM after a little more time to allow any inflammation to settle down.

There are a few studies similar in design to our research. First, Verveer et al. [30] found that inflammation may result in high LS values, especially for patients in F1 or F2 stage fibrosis. However, this study differed from ours in that only patients with HBV and HCV were included. In addition, patients with a fivefold increase or more in ALT were included and this factor was not mentioned in terms of the change in LS value. Second, Liang et al. [31] found that a decline of liver stiffness is related with both liver inflammation and fibrosis. Paired biopsy results were also reported for $30 \%$ of patients. However, only patients with chronic hepatitis B were included and the follow-up period was set to two years, which was shorter than in our study. Finally, the study of Fraquelli et al. [27], mentioned above, was similar to our study in that necroinflammatory activity was seen to be a main determinant of TE. However, they did not mention any correlation between histologic findings and a change of LS value.

This study adds some knowledge that is not well understood in previous studies. First, it is well-known that LS values can be overestimated by inflammation if the ALT level is higher than about $200 \mathrm{IU} / \mathrm{L}$ in current clinical practice $[7,8,18,32]$. However, as seen in this study, patients with low ALT may have some degree of histological inflammation, and LS values may not be accurate in this situation. Second, baseline inflammation has a significant effect on longitudinal change in LS value. In patients with the same baseline LS value, patients with LS improvement over time are likely to have more severe initial histologic inflammation than those without improvement. In other words, the degree of inflammation has a significant effect on the LS value, regardless of the ALT level, and also has a significant effect on the change of the LS value.

In the case of F4 fibrosis, it was significantly correlated with baseline LS value as a snapshot, but it was not associated with how much LS value would be decreased or increased over time. This could be explained by two reasons. First, our study included heterogeneous etiology in addition to HBV and HCV. Second, in patients with antiviral therapy, we only included patients who received treatment for more than one year. The phenomenon of decreased LS value in patients taking antiviral treatment is mainly reported in early phase of antiviral treatment [33]. Therefore, the patients included in our study were likely to have relatively less improvement in TE values. A similar observation was also found with steatosis, where it does not influence the baseline LS value or change of LS value at one year, but severe steatosis does influence liver stiffness at three-year follow-up. This may be due to two reasons. First, severe steatosis has been reported to overestimate LS values [34,35], whereas mild to moderate steatosis has no significant effect on LSM value [36]. Second, it can be presumed that weight change has occurred more greatly in patients with severe steatosis over the course of three years. Unfortunately, we could not get enough information about weight change to analyze this association on account of it being a retrospective study.

There are some caveats to consider while interpreting our results. First, although we collected data prospectively according to protocol, they were analyzed retrospectively. Thus, selection bias is inevitable because of the lack of follow-up results in many patients. On the other hand, the strength of this study is that we got baseline histologic information and repeated liver stiffness measurement from all participants. Second, we did not perform paired liver biopsies on all patients. However, we presented repeated liver biopsy results together with corresponding LS values in a subgroup analysis. Although these results were not statistically significant due to the small sample size, the impact of inflammation on change in LS value could be supported. Third, this is a multicenter study in which several different pathologists made the pathologic readings, so we cannot confirm agreement between 
them. Finally, we did not evaluate alcohol consumption or weight change during follow-up testing, which could be confounding variables.

In summary, although LS is a relatively accurate method for assessing liver fibrosis in chronic liver disease, histologic hepatic inflammation has a significant impact on baseline measurement of LS values and their improvement. Therefore, initial LS values should be interpreted with caution since they are affected not only by fibrosis, but also by inflammation, even if it is at low degree of ALT level $(<40 \mathrm{IU} / \mathrm{L})$.

Supplementary Materials: The following are available online at http:/www.mdpi.com/2077-0383/8/12/2065/s1, Supplementary Table S1. Univariable and multivariable linear regression analyses for liver stiffness measurement in transient elastography with alanine aminotransferase lower than $40 \mathrm{IU} / \mathrm{L}$. Supplementary Table S2. Linear regression analysis for 1-year liver stiffness value change amount (sensitivity analysis). Supplementary Table S3. Linear regression analysis for 3-year liver stiffness value change amount (sensitivity analysis). Supplementary S4. Characteristics of patients with paired liver biopsy and liver stiffness measurements. Supplementary Figure S1. Distribution of baseline liver stiffness values according to fibrosis stage and inflammation grade.

Author Contributions: Conceptualization: S.G.K., and J.-J.Y.; methodology: Y.S.S. and J.-J.Y.; formal analysis: B.L.; investigation: Y.S.K. and S.W.J.; resources: J.Y.J., S.J.S., and H.J.Y.; data curation: K.T.S., and S.U.K.; writing —original draft preparation, J.-J.Y.; writing—review and editing, J.-J.Y.; visualization, B.L.; supervision, D.J.K., K.-H.H., and S.G.K.

Funding: This work was supported by the Soonchunhyang University Research Fund.

Acknowledgments: We thank Eun-Ae Jung (Librarian, Medical Library, Soonchunhyang University Bucheon Hospital) for carefully proofreading the manuscript. We wish to acknowledge the help provided by The Korean Transient Elastography Study Group members (Oh Sang Kwon, Sang Heon Lee, Tae Hee Lee, Se Young Jang, Byoung Kuk Jang, Han Ah Lee, Byung Seok Kim, Ki Tae Yoon, Young Mi Hong, Eun Sun Jang, Jeong-Hoon LEE, Won-suk Kang, Soon Sun Kim, Hyo Jung Cho, Jung Il Lee, Hyun Woong Lee, Moon Young Kim, Seong Hee Kang, Jung Woo Shin, Hwi Young Kim, Eileen Yoon, Nae-Yun Heo, Jin Woo Lee, Seong Beom Cho, Chung Hwan Jun, In Hee Kim, Hyung Joon Kim, Young Eun Chon, Byung Seok Lee, Young Nam Kim, Sung-Eun Kim, Dae Won Jeon).

Conflicts of Interest: The authors declare no conflict of interest.

\section{References}

1. Mueller, S.; Millonig, G.; Sarovska, L.; Friedrich, S.; Reimann, F.M.; Pritsch, M.; Eisele, S.; Stickel, F.; Longerich, T.; Schirmacher, P.; et al. Increased liver stiffness in alcoholic liver disease: Differentiating fibrosis from steatohepatitis. World J. Gastroenterol. 2010, 16, 966-972. [CrossRef]

2. Mueller, S.; Sandrin, L. Liver stiffness: A novel parameter for the diagnosis of liver disease. Hepat. Med. 2010, 2, 49-67. [CrossRef] [PubMed]

3. Kim, S.U.; Kim, J.K.; Park, Y.N.; Han, K.H. Discordance between liver biopsy and Fibroscan(R) in assessing liver fibrosis in chronic hepatitis b: Risk factors and influence of necroinflammation. PLoS ONE 2012, 7, e32233. [CrossRef] [PubMed]

4. Kuo, Y.H.; Lu, S.N.; Chen, C.H.; Chang, K.C.; Hung, C.H.; Tai, W.C.; Tsai, M.C.; Tseng, P.L.; Hu, T.H.; Wang, J.H. The changes of liver stiffness and its associated factors for chronic hepatitis B patients with entecavir therapy. PLoS ONE 2014, 9, e93160. [CrossRef] [PubMed]

5. Buzzetti, E.; Kalafateli, M.; Thorburn, D.; Davidson, B.R.; Tsochatzis, E.; Gurusamy, K.S. Interventions for hereditary haemochromatosis: An attempted network meta-analysis. Cochrane Database Syst. Rev. 2017, 3. [CrossRef]

6. Yo, I.K.; Kwon, O.S.; Park, J.W.; Lee, J.J.; Lee, J.H.; Won, I.S.; Na, S.Y.; Jang, P.K.; Park, P.H.; Choi, D.J.; et al. The factors associated with longitudinal changes in liver stiffness in patients with chronic hepatitis B. Clin. Mol. Hepatol. 2015, 21, 32-40. [CrossRef]

7. Arena, U.; Vizzutti, F.; Corti, G.; Ambu, S.; Stasi, C.; Bresci, S.; Moscarella, S.; Boddi, V.; Petrarca, A.; Laffi, G.; et al. Acute viral hepatitis increases liver stiffness values measured by transient elastography. Hepatology 2008, 47, 380-384. [CrossRef]

8. Coco, B.; Oliveri, F.; Maina, A.M.; Ciccorossi, P.; Sacco, R.; Colombatto, P.; Bonino, F.; Brunetto, M.R. Transient elastography: A new surrogate marker of liver fibrosis influenced by major changes of transaminases. J. Viral Hepat. 2007, 14, 360-369. [CrossRef] 
9. Ishak, K.; Baptista, A.; Bianchi, L.; Callea, F.; De Groote, J.; Gudat, F.; Denk, H.; Desmet, V.; Korb, G.; MacSween, R.N.; et al. Histological grading and staging of chronic hepatitis. J. Hepatol. 1995, 22, 696-699. [CrossRef]

10. Mirza, S.; Siddiqui, A.R.; Hamid, S.; Umar, M.; Bashir, S. Extent of liver inflammation in predicting response to interferon alpha \& Ribavirin in chronic hepatitis C patients: A cohort study. BMC Gastroenterol. 2012, 12, 71. [CrossRef]

11. Hartl, J.; Denzer, U.; Ehlken, H.; Zenouzi, R.; Peiseler, M.; Sebode, M.; Hubener, S.; Pannicke, N.; Weiler-Normann, C.; Quaas, A.; et al. Transient elastography in autoimmune hepatitis: Timing determines the impact of inflammation and fibrosis. J. Hepatol. 2016, 65, 769-775. [CrossRef] [PubMed]

12. Sandrin, L.; Fourquet, B.; Hasquenoph, J.M.; Yon, S.; Fournier, C.; Mal, F.; Christidis, C.; Ziol, M.; Poulet, B.; Kazemi, F.; et al. Transient elastography: A new noninvasive method for assessment of hepatic fibrosis. Ultrasound Med. Biol. 2003, 29, 1705-1713. [CrossRef] [PubMed]

13. Castéra, L.; Vergniol, J.; Foucher, J.; Le Bail, B.; Chanteloup, E.; Haaser, M.; Darriet, M.; Couzigou, P.; De Lédinghen, V. Prospective comparison of transient elastography, Fibrotest, APRI, and liver biopsy for the assessment of fibrosis in chronic hepatitis C. Gastroenterology 2005, 128, 343-350. [CrossRef] [PubMed]

14. Wong, V.W.; Wong, G.L.; Choi, P.C.; Chan, A.W.; Li, M.K.; Chan, H.Y.; Chim, A.M.; Yu, J.; Sung, J.J.; Chan, H.L. Disease progression of non-alcoholic fatty liver disease: A prospective study with paired liver biopsies at 3 years. Gut 2010, 59, 969-974. [CrossRef] [PubMed]

15. Kim, G.; Kim, M.Y.; Baik, S.K. Transient elastography versus hepatic venous pressure gradient for diagnosing portal hypertension: A systematic review and meta-analysis. Clin. Mol. Hepatol. 2017, 23, 34-41. [CrossRef] [PubMed]

16. Zeng, X.; Xu, C.; He, D.; Zhang, H.; Xia, J.; Shi, D.; Kong, L.; He, X.; Wang, Y. Influence of hepatic inflammation on fibroscan findings in diagnosing fibrosis in patients with chronic hepatitis B. Ultrasound Med. Biol. 2015, 41, 1538-1544. [CrossRef]

17. Raizner, A.; Shillingford, N.; Mitchell, P.D.; Harney, S.; Raza, R.; Serino, J.; Jonas, M.M.; Lee, C.K. Hepatic inflammation may influence liver stiffness measurements by transient elastography in children and young adults. J. Pediatr. Gastroenterol. Nutr. 2017, 64, 512-517. [CrossRef]

18. Sagir, A.; Erhardt, A.; Schmitt, M.; Haussinger, D. Transient elastography is unreliable for detection of cirrhosis in patients with acute liver damage. Hepatology 2008, 47, 592-595. [CrossRef]

19. Shafaei, S.; Soleimani Amiri, S.; Hajiahmadi, M.; Sadeghi-Haddad-Zavareh, M.; Bayani, M. Histological grading and staging of liver and its relation to viral loads in chronic anti-HBe positive hepatitis. Casp. J. Intern. Med. 2013, 4, 681-685.

20. Brunt, E.M.; Kleiner, D.E.; Wilson, L.A.; Unalp, A.; Behling, C.E.; Lavine, J.E.; Neuschwander-Tetri, B.A. Portal chronic inflammation in nonalcoholic fatty liver disease (NAFLD): A histologic marker of advanced NAFLD-Clinicopathologic correlations from the nonalcoholic steatohepatitis clinical research network. Hepatology 2009, 49, 809-820. [CrossRef]

21. Sanai, F.M.; Benmousa, A.; Al-Hussaini, H.; Ashraf, S.; Alhafi, O.; Abdo, A.A.; Alameri, H.F.; Akbar, H.O.; Bzeizi, K.I. Is serum alanine transaminase level a reliable marker of histological disease in chronic hepatitis $\mathrm{C}$ infection? Liver Int. 2008, 28, 1011-1018. [CrossRef] [PubMed]

22. Shi, J.P.; Xun, Y.H.; Hu, C.B.; Zhang, L.; Liu, H.; Lou, G.Q.; Fan, J.G. Clinical and histological features of non-alcoholic fatty liver disease. Chin. J. Hepatol. 2009, 17, 812-816.

23. Kyrlagkitsis, I.; Portmann, B.; Smith, H.; O'Grady, J.; Cramp, M.E. Liver histology and progression of fibrosis in individuals with chronic hepatitis C and persistently normal ALT. Am. J. Gastroenterol. 2003, 98, 1588-1593. [CrossRef] [PubMed]

24. Hartl, J.; Ehlken, H.; Weiler-Normann, C.; Sebode, M.; Kreuels, B.; Pannicke, N.; Zenouzi, R.; Glaubke, C.; Lohse, A.W.; Schramm, C. Patient selection based on treatment duration and liver biochemistry increases success rates after treatment withdrawal in autoimmune hepatitis. J. Hepatol. 2015, 62, 642-646. [CrossRef]

25. Goodman, Z.D. Grading and staging systems for inflammation and fibrosis in chronic liver diseases. J. Hepatol. 2007, 47, 598-607. [CrossRef]

26. Dhaliwal, H.K.; Hoeroldt, B.S.; Dube, A.K.; McFarlane, E.; Underwood, J.C.; Karajeh, M.A.; Gleeson, D. Long-term prognostic significance of persisting histological activity despite biochemical remission in autoimmune hepatitis. Am. J. Gastroenterol. 2015, 110, 993-999. [CrossRef] 
27. Fraquelli, M.; Rigamonti, C.; Casazza, G.; Donato, M.F.; Ronchi, G.; Conte, D.; Rumi, M.; Lampertico, P.; Colombo, M. Etiology-related determinants of liver stiffness values in chronic viral hepatitis B or C. J. Hepatol. 2011, 54, 621-628. [CrossRef]

28. Kim, S.U.; Seo, Y.S.; Cheong, J.Y.; Kim, M.Y.; Kim, J.K.; Um, S.H.; Cho, S.W.; Paik, S.K.; Lee, K.S.; Han, K.H.; et al. Factors that affect the diagnostic accuracy of liver fibrosis measurement by Fibroscan in patients with chronic hepatitis B. Aliment. Pharmacol. Ther. 2010, 32, 498-505. [CrossRef]

29. Myers, R.P.; Crotty, P.; Pomier-Layrargues, G.; Ma, M.; Urbanski, S.J.; Elkashab, M. Prevalence, risk factors and causes of discordance in fibrosis staging by transient elastography and liver biopsy. Liver Int. 2010, 30, 1471-1480. [CrossRef]

30. Verveer, C.; Zondervan, P.E.; ten Kate, F.J.; Hansen, B.E.; Janssen, H.L.; de Knegt, R.J. Evaluation of transient elastography for fibrosis assessment compared with large biopsies in chronic hepatitis B and C. Liver Int. 2012, 32, 622-628. [CrossRef]

31. Liang, X.; Xie, Q.; Tan, D.; Ning, Q.; Niu, J.; Bai, X.; Chen, S.; Cheng, J.; Yu, Y.; Wang, H.; et al. Interpretation of liver stiffness measurement-based approach for the monitoring of hepatitis B patients with antiviral therapy: A 2-year prospective study. J. Viral Hepat. 2018, 25, 296-305. [CrossRef] [PubMed]

32. Tapper, E.B.; Cohen, E.B.; Patel, K.; Bacon, B.; Gordon, S.; Lawitz, E.; Nelson, D.; Nasser, I.A.; Challies, T.; Afdhal, N. Levels of alanine aminotransferase confound use of transient elastography to diagnose fibrosis in patients with chronic hepatitis C virus infection. Clin. Gastroenterol. Hepatol. 2012, 10, 932-937.e1. [CrossRef] [PubMed]

33. Chekuri, S.; Nickerson, J.; Bichoupan, K.; Sefcik, R.; Doobay, K.; Chang, S.; DelBello, D.; Harty, A.; Dieterich, D.T.; Perumalswami, P.V.; et al. Liver Stiffness Decreases Rapidly in Response to Successful Hepatitis C Treatment and Then Plateaus. PLoS ONE 2016, 11, e0159413. [CrossRef] [PubMed]

34. Petta, S.; Maida, M.; Macaluso, F.S.; Di Marco, V.; Camma, C.; Cabibi, D.; Craxi, A. The severity of steatosis influences liver stiffness measurement in patients with nonalcoholic fatty liver disease. Hepatology 2015, 62, 1101-1110. [CrossRef]

35. Macaluso, F.S.; Maida, M.; Camma, C.; Cabibbo, G.; Cabibi, D.; Alduino, R.; Di Marco, V.; Craxi, A.; Petta, S. Steatosis affects the performance of liver stiffness measurement for fibrosis assessment in patients with genotype 1 chronic hepatitis C. J. Hepatol. 2014, 61, 523-529. [CrossRef]

36. Kim, S.U.; Kim, D.Y.; Ahn, S.H.; Kim, H.M.; Lee, J.M.; Chon, C.Y.; Park, Y.N.; Han, K.H.; Park, J.Y. The impact of steatosis on liver stiffness measurement in patients with chronic hepatitis B. Hepato-Gastroenterol. 2010, 57, 832-838.

(C) 2019 by the authors. Licensee MDPI, Basel, Switzerland. This article is an open access article distributed under the terms and conditions of the Creative Commons Attribution (CC BY) license (http://creativecommons.org/licenses/by/4.0/). 